\title{
Cholangiocarcinoma Presenting after Eight Years of Treatment of IgG4-Related Autoimmune Pancreatitis with Steroids
}

\author{
Hiroharu Shinozaki ${ }^{a}$ Yuuichi Sasakura ${ }^{a}$ Satoshi Shinozaki ${ }^{b, c}$ \\ Toshiaki Terauchi $^{\mathrm{a}}$ Junichi Matsui ${ }^{\mathrm{d}}$ Kenji Kobayashi ${ }^{\mathrm{a}}$ \\ Alan Kawarai Lefor ${ }^{\mathrm{e}}$ Yoshiro Ogata ${ }^{\mathrm{a}}$
}

aDepartment of Surgery, Saiseikai Utsunomiya Hospital, Utsunomiya, Japan; bShinozaki Medical Clinic, Utsunomiya, Japan; 'Division of Gastroenterology, Department of Medicine, Jichi Medical University, Shimotsuke, Japan; dDepartment of Surgery, Tokyo

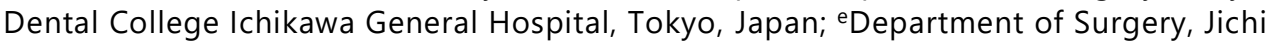
Medical University, Shimotsuke, Japan

\section{Keywords}

Cholangiocarcinoma · Autoimmune pancreatitis - Immunoglobulin G4-related disease ·

Steroids · Inflammation · Carcinogenesis

\begin{abstract}
Autoimmune pancreatitis (AIP) is characterized by pancreatic manifestations of IgG4-related disease. Malignancies in patients with AIP have been reported, but carcinoma of the bile duct is extremely rare. We report a patient with IgG4-related AIP who developed cholangiocarcinoma after 8 years of steroid treatment. A 76 -year-old male presented with fever $\left(37.8^{\circ} \mathrm{C}\right)$ due to biliary obstruction and cholangitis. He had been treated with steroids for 8 years to control inflammation due to IgG4-related AIP. During 8 years of treatment, hepatobiliary enzyme levels were well controlled within their normal range, but serum IgG4 levels remained elevated. A
\end{abstract}

\begin{tabular}{ll}
\hline & Satoshi Shinozaki \\
Sarginozaki Medical Clinic & \\
& $6-1-13$ Kiyoharadai \\
Utsunomiya, Tochigi 321-3223 (Japan) & shinozaki-s@aqua.ocn.ne.jp
\end{tabular}




\section{Case Reports in Gastroenterology}

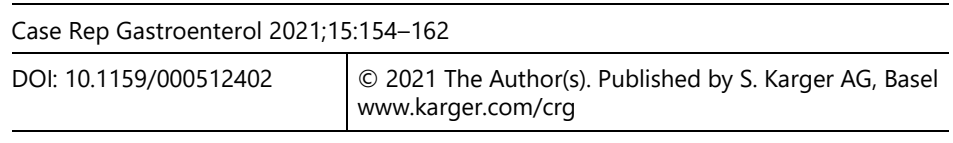

Shinozaki et al.: Autoimmune Pancreatitis Complicated by Cholangiocarcinoma

computed tomography scan showed intrahepatic bile duct dilatation. Magnetic resonance cholangiopancreatography showed obstructive changes at the junction of the cystic and common ducts. To relieve biliary obstruction, endoscopic bile duct drainage using a nasobiliary tube was performed, and cytology was Class IV. Aorto-caval lymph node enlargement was found at laparotomy, intraoperatively diagnosed as adenocarcinoma, and resection was abandoned. He died 4 months postoperatively. We report a patient with IgG4-related AIP complicated by cholangiocarcinoma which developed after 8 years of steroid treatment. Even if hepatobiliary markers are well controlled, periodic follow-up with imaging studies may facilitate detection of an early cholangiocarcinoma.

(C) 2021 The Author(s) Published by S. Karger AG, Basel

\section{Introduction}

Autoimmune pancreatitis (AIP) is characterized by pancreatic manifestations of IgG4-related disease, and $87 \%$ of patients with IgG4-related sclerosing cholangitis develop AIP [1]. Despite the unclear etiology of chronic inflammation and fibrosis, high serum IgG4 levels and hypergammaglobulinemia suggest an autoimmune mechanism [2]. AIP is considered to be a pancreatic lesion of IgG4-related diseases. The histology shows lymphoplasmacytic sclerosing pancreatitis characterized by prominent lymphocyte and plasma cell infiltration, storiform fibrosis, obliterative phlebitis, and IgG4-positive plasma cell infiltration [3, 4]. AIP is a comparatively rare disease, and the prevalence and morbidity in Japan are 4.6 and 1.4 per 100,000, respectively [5].

Malignancies have been reported in patients with AIP. The most common interval for the diagnosis of cancer is within 1 year after the diagnosis of AIP, and the most frequently reported malignancies were not in the pancreas itself but in other organs including gastric, lung and prostate cancers [6]. Malignancy of the bile duct in patients with AIP is extremely rare. In one report, only 1 patient (3\%) had biliary tract cancer out of 30 patients reported with malignancies complicating AIP [7]. Few reports of cholangiocarcinoma in patients with AIP are available. We report a patient with IgG4-related AIP complicated by cholangiocarcinoma diagnosed after 8 years of steroid treatment.

\section{Case Report}

A 76-year-old male presented with dizziness, chills, and fever $\left(37.8^{\circ} \mathrm{C}\right)$. He had been treated with steroid therapy (prednisolone 5-10 mg once daily) for 8 years to control inflammation due to IgG4-related AIP. At the initial diagnosis of AIP, there were no findings of sclerosing cholangitis on computed tomography (CT) scan or magnetic resonance cholangiopancreatography (MRCP). During the 8-year treatment period, alanine aminotransferase, alkaline phosphatase, and $\gamma$-glutamyl transpeptidase were controlled within their normal range, but serum IgG4 levels remained elevated at more than $600 \mathrm{mg} / \mathrm{dL}$ (Fig. 1). He developed metachronous prostate cancer treated by radiation therapy 5 years after the diagnosis of AIP. On

\section{Karger'=}




\section{Case Reports in Gastroenterology}

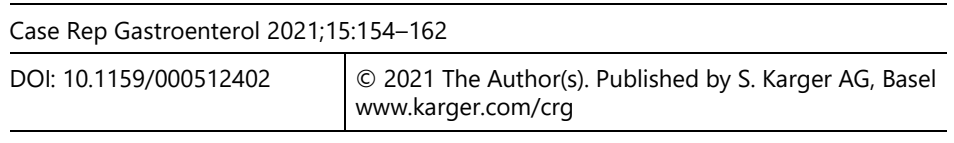

Shinozaki et al.: Autoimmune Pancreatitis Complicated by Cholangiocarcinoma

admission, laboratory data showed elevated hepatobiliary enzymes (Table 1). Serum IgG4 was not remarkably elevated compared to previous levels (Fig. 1). A CT scan showed intrahepatic bile duct dilatation, and positron emission tomography showed fluorodeoxyglucose accumulation in local and para-aortic lymph nodes (Fig. 2). MRCP showed obstructive changes at the junction of the cystic and common hepatic ducts (Fig. 3). To relieve the biliary obstruction, endoscopic bile duct drainage using a nasobiliary tube was performed (Fig. 3), the cytology of the bile was Class IV, and laparotomy was scheduled. The preoperative diagnosis was bile duct cancer complicating AIP (clinical stage IIB). At laparotomy, enlarged aorto-caval lymph nodes (Fig. 4) were found, and an intraoperative diagnosis showed metastatic adenocarcinoma. Therefore, resection was abandoned, and the postoperative diagnosis was cholangiocarcinoma (surgical stage IV). Despite chemotherapy using S-1, he died 4 months after laparotomy.

\section{Discussion}

We report a patient who developed cholangiocarcinoma after 8 years of steroid therapy for IgG4-related AIP. As neoplasms develop complicating autoimmune diseases, persistent inflammation and paraneoplastic syndrome are suggested as pathogenetic factors. Considering the interval between the onset of AIP and cholangiocarcinoma developing in the present patient, the AIP is not felt to be part of a paraneoplastic syndrome. Persistent inflammation involving the bile duct for 8 years is considered to be the main cause of the development of cholangiocarcinoma. During the 8-year clinical course, the value of alanine aminotransferase was maintained below $30 \mathrm{U} / \mathrm{L}$. Although there are no specific markers of pancreatic inflammation, IgG4 value neither decreased nor went down to the normal range during the steroid therapy. Currently, serum IgG4 value is not considered to be a target marker to monitor the activity of AIP, but it may reflect autoimmune activity and carcinogenesis. Further studies are necessary to clarify the relationship between changes in IgG4 levels and AIP-related inflammation. Additional therapies such as immunomodulators may be useful to control inflammation and limit the development of neoplasms.

Generally, AIP is associated with the development of gastric, lung, and prostate cancer [6], and the present patient had metachronous prostate cancer treated by radiation therapy during the steroid therapy. Cholangiocarcinoma developing in patients with AIP is extremely rare. From 2008 to 2020, 10 patients have been reported including the present patient (Table 2) [8-16]. Nine of the $10(90 \%)$ were male. In 6/10 (60\%) patients, AIP and cholangiocarcinoma were diagnosed simultaneously, so in these patients AIP was considered as part of a paraneoplastic syndrome. Eight of the 10 patients (80\%) underwent resection, but the present patient was unresectable due to the presence of metastatic disease identified intraoperatively. Unfortunately, CT scans and MRCP were rarely performed during the 8-year interval between the diagnosis of AIP and the diagnosis of cholangiocarcinoma in the present patient. Retrospectively, periodic follow-up with appropriate imaging studies may have allowed early detection of the cholangiocarcinoma. In patients with AIP, a K-ras mutation is frequently observed in the common bile duct and gallbladder epithelium [17]. As a limitation of this case

\section{Karger'=}




\section{Case Reports in Gastroenterology}

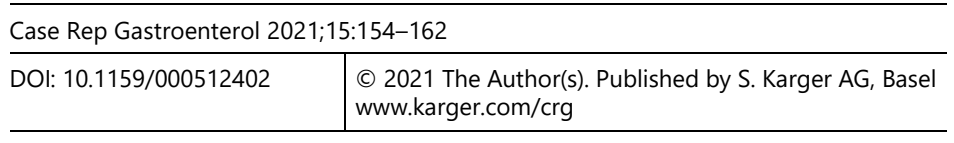

Shinozaki et al.: Autoimmune Pancreatitis Complicated by Cholangiocarcinoma

report, detailed pathological studies of the cholangiocarcinoma lesion were not performed due to the inability to perform a surgical resection.

In conclusion, we report a patient with cholangiocarcinoma complicating the diagnosis of IgG4-related AIP after 8 years of steroid treatment. Even if hepatobiliary markers are well controlled, periodic imaging studies are important to detect early stage cholangiocarcinoma. Considering the difficult differential diagnosis between cholangiocarcinoma and sclerosing cholangitis, we recommend performing MRCP and/or CT scan at least annually.

\section{Statement of Ethics}

Written informed consent was obtained from the participant involved in the study for publication of this case report and any accompanying images.

\section{Conflict of Interest Statement}

The authors have no conflicts of interest to declare.

\section{Funding Sources}

None.

\section{Author Contributions}

Hiroharu Shinozaki and Satoshi Shinozaki drafted and wrote the manuscript. Yuuichi Sasakura and Toshiaki Terauchi acquired the data. Junichi Matsui, Kenji Kobayashi, Alan Kawarai Lefor and Yoshiro Ogata revised it critically for important intellectual content. All authors read and approved the final version of the manuscript.

\section{References}

1 Tanaka A, Tazuma S, Okazaki K, Nakazawa T, Inui K, Chiba T, et al. Clinical Features, Response to Treatment, and Outcomes of IgG4-Related Sclerosing Cholangitis. Clin Gastroenterol Hepatol. 2017 Jun;15(6):920926.e3.

2 Hamano H, Kawa S, Horiuchi A, Unno H, Furuya N, Akamatsu T, et al. High serum IgG4 concentrations in patients with sclerosing pancreatitis. N Engl J Med. 2001 Mar;344(10):732-8.

3 Kamisawa T, Funata N, Hayashi Y, Tsuruta K, Okamoto A, Amemiya K, et al. Close relationship between autoimmune pancreatitis and multifocal fibrosclerosis. Gut. 2003 May;52(5):683-7.

4 Matsubayashi H, Kakushima N, Takizawa K, Tanaka M, Imai K, Hotta K, et al. Diagnosis of autoimmune pancreatitis. World J Gastroenterol. 2014 Nov;20(44):16559-69. 


\section{Case Reports in Gastroenterology}

(c) 2021 The Author(s). Published by S. Karger AG, Basel www.karger.com/crg

Shinozaki et al.: Autoimmune Pancreatitis Complicated by Cholangiocarcinoma

5 Kanno A, Masamune A, Okazaki K, Kamisawa T, Kawa S, Nishimori I, et al.; Research Committee of Intractable Diseases of the Pancreas. Nationwide epidemiological survey of autoimmune pancreatitis in Japan in 2011. Pancreas. 2015 May;44(4):535-9.

6 Okamoto A, Watanabe T, Kamata K, Minaga K, Kudo M. Recent Updates on the Relationship between Cancer and Autoimmune Pancreatitis. Intern Med. 2019 Jun;58(11):1533-9.

7 Asano J, Watanabe T, Oguchi T, Kanai K, Maruyama M, Ito T, et al. Association Between Immunoglobulin G4related Disease and Malignancy within 12 Years after Diagnosis: An Analysis after Long-term Follow-up. J Rheumatol. 2015 Nov;42(11):2135-42.

8 Oh HC, Kim JG, Kim JW, Lee KS, Kim MK, Chi KC, et al. Early bile duct cancer in a background of sclerosing cholangitis and autoimmune pancreatitis. Intern Med. 2008;47(23):2025-8.

9 Kakinoki K, Okano K, Suzuki Y. A case of pancreatic cancer and lower bile duct cancer complicated with IgG4-related sclerosing disease [in Japanese]. Shujutsu. 2010;64(9):1333-7.

10 Ohtani H, Ishida H, Ito Y, Yamaguchi T, Koizumi M. Autoimmune pancreatitis and biliary intraepithelial neoplasia of the common bile duct: a case with diagnostically challenging but pathogenetically significant association. Pathol Int. 2011 Aug;61(8):481-5.

11 Kanomata H, Tachikawa N, Hara H, Matsuda S, Miyamoto K, Ito M, et al. A Case of Autoimmune Pancreatitis and lgG4-related Sclerosing Cholangitis with Bile Duct Cancer [in Japanese]. Tan to Sui. 2012;33(7):631-6.

12 Douhara A, Mitoro A, Otani E, Furukawa M, Kaji K, Uejima M, et al. Cholangiocarcinoma developed in a patient with IgG4-related disease. World J Gastrointest Oncol. 2013 Aug;5(8):181-5.

13 Maeda S, Marugami N, Anai H, Takahama K, Kichikawa K, Shou M, et al. Bile duct cancer from IgG4-related sclerosing cholangitis: CT and MRI findings [in Japanese]. Jpn J Clin Radiol. 2013;58:812-6.

14 Hasebe O, Ochi Y, Ito T, Narumoto S, Hosaka N. Cholangiocellular carcinoma developed in a patient with autoimmune pancreatitis and IgG4-related sclerosing cholangitis during long follow-up periods [in Japanese]. J Jpn Biliary Assoc. 2014;28(5):785-93.

15 Kamimukai N, Takahashi T, Nakajima T, Kobayashi A, Hirano S, Nagahori Y, et al. Cholangiocarcinoma with IgG4-related Sclerosing Cholangitis [in Japanese]. Nihon Shokaki Geka Gakkai Zasshi. 2016;49(3):207-15.

16 Koopman KE, Bloemena E, Kazemier G, Klemt-Kropp M. Immunoglobulin G4-mediated sclerosing cholangitis as a risk factor for cholangiocarcinoma: A case report. Mol Clin Oncol. 2016 Dec;5(6):786-8.

17 Kamisawa T, Tsuruta K, Okamoto A, Horiguchi S, Hayashi Y, Yun X, et al. Frequent and significant K-ras mutation in the pancreas, the bile duct, and the gallbladder in autoimmune pancreatitis. Pancreas. 2009 Nov;38(8):890-5. 


\section{Case Reports in Gastroenterology}

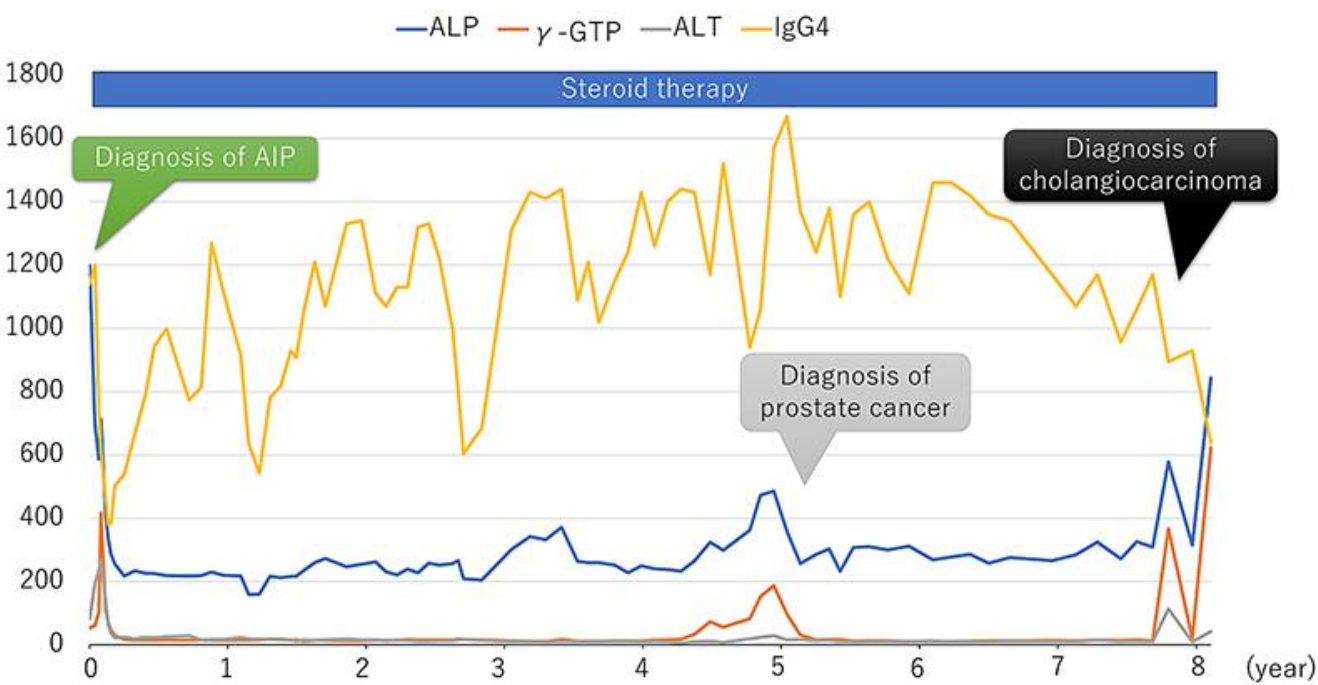

Fig. 1. Clinical course and changes in laboratory parameters during 8 years of steroid therapy to control IgG4-related autoimmune pancreatitis (AIP). Serum IgG4 (normal range, 4.8-105 mg/dL); ALP, alkaline phosphatase (115-359 U/L); $\gamma$-GTP, $\gamma$-glutamyl transpeptidase $(\leq 70 \mathrm{U} / \mathrm{L}), \mathrm{ALT}$, alanine aminotransferase (5-40 U/L).
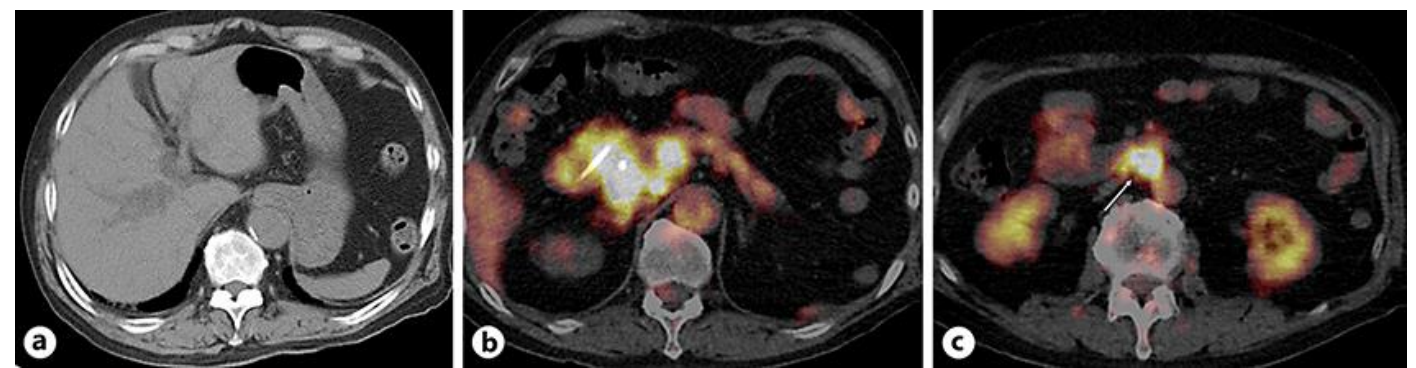

Fig. 2. a Computed tomography scan shows intrahepatic bile duct dilation. b-c Positron emission tomography shows fluorodeoxyglucose accumulation in lymph nodes around the bile duct (b) and a para-aortic lymph node (arrow, No. 16b1) (c). 


\section{Case Reports in Gastroenterology}

Case Rep Gastroenterol 2021;15:154-162 (c) 2021 The Author(s). Published by S. Karger AG, Basel www.karger.com/crg

Shinozaki et al.: Autoimmune Pancreatitis Complicated by Cholangiocarcinoma
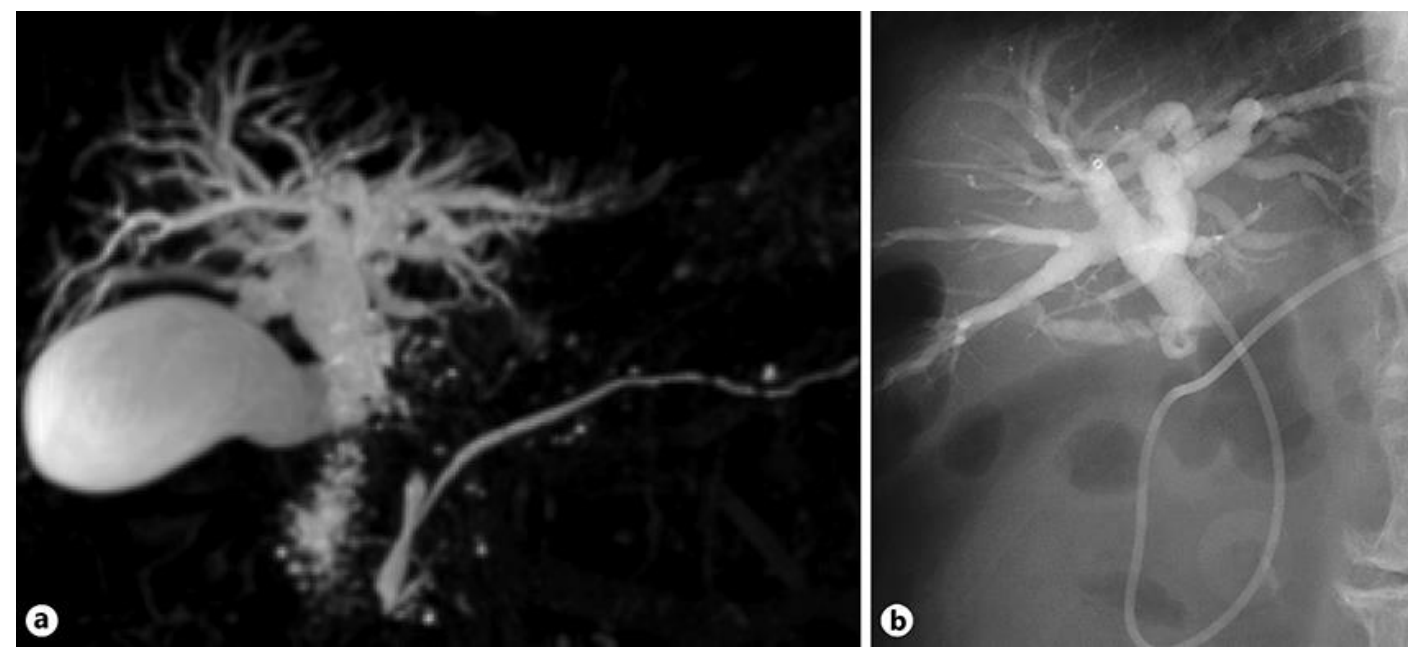

Fig. 3. An obstructive stricture at the junction of the cystic and common hepatic ducts on magnetic resonance cholangiography (a) and nasobiliary tube cholangiography (b).
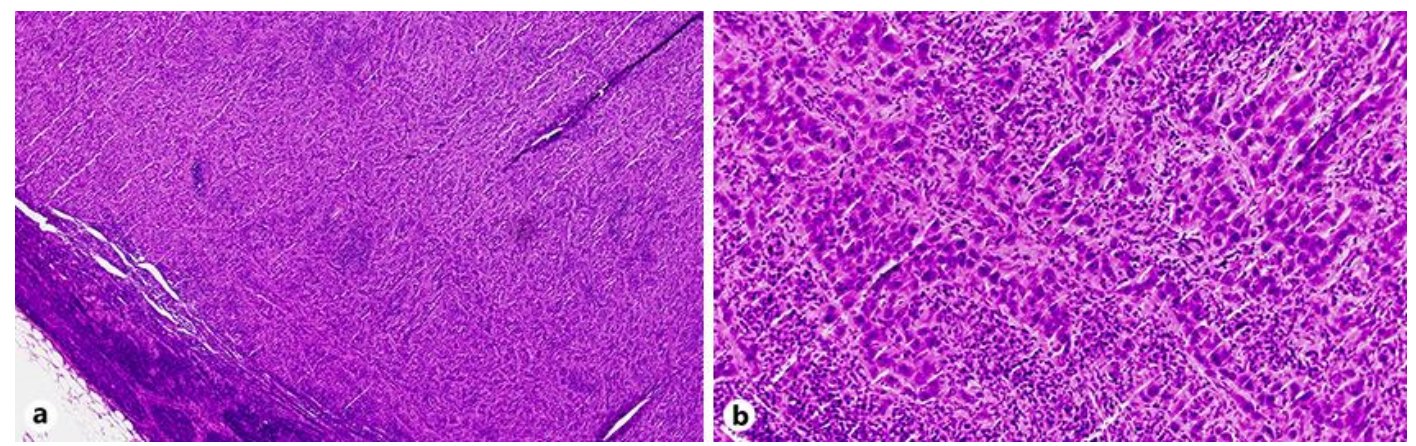

Fig. 4. Surgical specimen of a lymph node from the aorto-caval region. A proliferation of epithelioid cells with severe atypia is consistent with metastatic adenocarcinoma. Magnification $\times 40$ (a) and $\times 200$ (b), hematoxylin and eosin. 
Case Reports in Gastroenterology
Case Rep Gastroenterol 2021;15:154-162

(C) 2021 The Author(s). Published by S. Karger AG, Basel www.karger.com/crg

Shinozaki et al.: Autoimmune Pancreatitis Complicated by Cholangiocarcinoma

Table 1. Laboratory findings on admission

\begin{tabular}{lrl}
\hline & Value & Unit \\
\hline White blood cell & 12,650 & $/ \mathrm{mm}^{3}$ \\
Hemoglobin & 12.5 & $\mathrm{~g} / \mathrm{dL}$ \\
Platelet & 218,000 & $/ \mathrm{mm}^{3}$ \\
Total protein & 7.5 & $\mathrm{~g} / \mathrm{dL}$ \\
Albumin & 3.2 & $\mathrm{~g} / \mathrm{dL}$ \\
Total bilirubin & 1.5 & $\mathrm{mg} / \mathrm{dL}$ \\
Aspartate aminotransferase & 304 & $\mathrm{U} / \mathrm{L}$ \\
Alanine aminotransferase & 227 & $\mathrm{U} / \mathrm{L}$ \\
Alkaline phosphatase & 824 & $\mathrm{U} / \mathrm{L}$ \\
$\gamma$-Glutamyl transferase & 555 & $\mathrm{U} / \mathrm{L}$ \\
Amylase & 80 & $\mathrm{U} / \mathrm{L}$ \\
Blood urea nitrogen & 23.9 & $\mathrm{mg} / \mathrm{dL}$ \\
Creatinine & 1.79 & $\mathrm{mg} / \mathrm{dL}$ \\
Plasma glucose & 111 & $\mathrm{mg} / \mathrm{dL}$ \\
Hemoglobin A1c & 5.9 & $\%$ \\
Carcinoembryonic antigen & 2.3 & $\mathrm{ng} / \mathrm{dL}$ \\
Cancer antigen 19-9 & 601.4 & $\mathrm{U} / \mathrm{mL}$ \\
IgG4 & 895 & $\mathrm{mg} / \mathrm{dL}$ \\
\hline
\end{tabular}




\section{Case Reports in Gastroenterology}

\begin{tabular}{l|l}
\hline Case Rep Gastroenterol 2021;15:154-162 \\
\hline DOI: 10.1159/000512402 & $\begin{array}{l}\text { (c) 2021 The Author(s). Published by S. Karger AG, Basel } \\
\text { www.karger.com/crg }\end{array}$ \\
\hline
\end{tabular}

Shinozaki et al.: Autoimmune Pancreatitis Complicated by Cholangiocarcinoma

Table 2. Previously reported patients with autoimmune pancreatitis complicated by cholangiocarcinoma

\begin{tabular}{|c|c|c|c|c|c|c|c|}
\hline First author [Ref.] & Year & Age & Gender & Diagnosis of cancer & Location & Operation & Follow-up \\
\hline Oh [8] & 2008 & 59 & Male & Simultaneous & Lower & Resected & Not reported \\
\hline Kakinoki [9] & 2010 & 71 & Male & Simultaneous & Lower & Resected & $\begin{array}{l}\text { Died } 6 \text { months af- } \\
\text { ter resection }\end{array}$ \\
\hline Ohtani [10] & 2011 & 64 & Male & Simultaneous & Lower & Resected & $\begin{array}{l}\text { Alive } 8 \text { years after } \\
\text { resection }\end{array}$ \\
\hline Kanomata [11] & 2012 & 62 & Male & Simultaneous & Lower & Resected & Not reported \\
\hline Douhara [12] & 2013 & 77 & Male & $\begin{array}{l}\text { After } 4 \text { years of } \\
\text { steroid Tx }\end{array}$ & Middle & Resected & Not reported \\
\hline Maeda [13] & 2013 & 78 & Male & $\begin{array}{l}\text { After } 4 \text { years of } \\
\text { steroid Tx }\end{array}$ & Hilar & Resected & Not reported \\
\hline Hasebe [14] & 2014 & 81 & Male & \multicolumn{2}{|c|}{$\begin{array}{l}\text { After } 15 \text { years of steroid Hilar } \\
\text { Tx }\end{array}$} & No operation & $\begin{array}{l}\text { Died } 9 \text { months af- } \\
\text { ter diagnosis }\end{array}$ \\
\hline Koopman [16] & 2016 & 43 & Female & Simultaneous & Middle & Resected & $\begin{array}{l}\text { Alive } 3 \text { months af- } \\
\text { ter resection }\end{array}$ \\
\hline Kamimukai [15] & 2016 & 64 & Male & Simultaneous & Lower & Resected & $\begin{array}{l}\text { Alive } 2 \text { years after } \\
\text { resection }\end{array}$ \\
\hline $\begin{array}{l}\text { Shinozaki } \\
\text { (present patient) }\end{array}$ & 2020 & 76 & Male & $\begin{array}{l}\text { After } 8 \text { years of } \\
\text { steroid Tx }\end{array}$ & Middle & $\begin{array}{l}\text { Exploratory lapa } \\
\text { rotomy }\end{array}$ & $\begin{array}{l}\text {-Died } 4 \text { months af- } \\
\text { ter laparotomy }\end{array}$ \\
\hline
\end{tabular}

Tx, treatment. 